\title{
Contribuições e Limites do Uso da Abordagem Centrada na Pessoa para a Fundamentação Teórica do Aconselhamento em DST/Aids
}

\author{
Ligia Rivero Pupo ${ }^{1}$ \\ Instituto de Saúde da Secretaria de Estado de Saúde de São Paulo, São Paulo, Brasil \\ José Ricardo Carvalho Mesquita Ayres \\ Faculdade de Medicina da Universidade de São Paulo, São Paulo, Brasil
}

\begin{abstract}
Resumo
Mesmo sendo uma importante tecnologia de prevenção, estudos nacionais e internacionais indicam que o aconselhamento no campo das DST/aids, apresenta fragilidades e problemas, entre eles, a carência de fundamentação teórica ou inconsistências entre bases teóricas e desdobramentos técnicos. Este estudo pretendeu examinar as contribuições conceituais de um dos quadros teóricos que influenciaram a construção de estratégias e técnicas de aconselhamento em DST no Brasil, a Abordagem Centrada na Pessoa (ACP), de Carl Rogers, assim como as limitações de seu uso no âmbito das DST/aids, a partir da análise de documentos produzidos pela Organização Mundial de Saúde, Programa de Aids das Nações Unidas (UNAIDS), e Ministério da Saúde - Brasil, tidos como as principais referências normativas para o aconselhamento. Tratou-se o material documental de forma interpretativa, cotejando-se as construções conceituais rogerianas com os componentes do processo de trabalho recomendado nos documentos, examinando-se sua consistência e coerência internas. Evidenciaram-se incompatibilidades em relação aos objetivos, foco, resultados esperados e postura do profissional. Tais desacordos parecem decorrer de diferenças entre as finalidades originais do aconselhamento baseado na ACP e aquelas demandadas nas estratégias de prevenção às DST/aids. A confluência de diversas finalidades colocadas ao aconselhamento no campo das DST/aids, configuram obstáculos a um uso consistente da ACP. Conclui-se pela pertinência e interesse da abordagem rogeriana no aconselhamento como técnica de apoio para tomada de decisões e manejo de situações cotidianas no campo da prevenção, mas aponta-se a necessidade de rever objetivos e procedimentos padronizados voltados à mudança de comportamento e a vigilância epidemiológica.
\end{abstract}

Palavras-chave: Aconselhamento, síndrome da imunodeficiência adquirida, doenças sexualmente transmissíveis, modelos teóricos, abordagem centrada na pessoa, Carl Rogers, estratégias de prevenção.

\section{Contributions and Limits of the Use of Person-Centered Therapy (PCT) for the Theoretical Foundation of STD/Aids Counseling}

\begin{abstract}
Although it figures as an important prevention technology, national and international studies point out that counseling in the STD/AIDS field present frailties and problems, among them the lack of theoretical grounds or inconsistencies among theoretical bases and technical developments. This study aimed to examine the conceptual contribution of one of the theoretical frames that influenced the construction of counseling strategies and techniques in STD in Brazil, the Person-centered therapy (PCT), developed
\end{abstract}

Endereço para correspondência: Av. Dr. Arnaldo, 355, Consolação, São Paulo, SP, Brasil 01246-000. E-mail: ligia@isaude.sp.gov.br e jrcayres@usp.br 
by Carl Rogers, as well as the limits of its employment in the STD/AIDS context, from the analysis of documents produced by the World Health Organization, the Joint United Nations Program on HIV/ AIDS (UNAIDS), and Ministry of Health - Brazil, regarded as the main normative references for counseling. The documentary material was approached interpretively, the rogerian conceptual constructions compared with the work process recommended in the documents, examining its consistence and internal coherence. Incompatibilities were evidenced regarding their objectives, focus, expected results and professional attitude. Such disagreements seem to stem from differences among the original aims of PCT-based counseling and those demanded in STD/AIDS prevention strategies. The confluence of many goals added to counseling in the field of STD/AIDS presented complications to a consistent use of the PCT. The study agrees with the pertinence and interest of the rogerian approach in counseling as a support technique for the decision making and management of everyday situations in the field of prevention, but the need to revise objectives and standardized procedures focused on behavioral change and epidemiological vigilance is also stressed.

Keywords: Counseling, acquired immunodeficiency syndrome, sexually transmitted diseases, theoretical models, person-centered therapy, Carl Rogers, prevention strategies.

\section{Aportaciones y Límites del Uso de la Abordaje Centrada en la Persona (ACP) para la Fundamentación Teórica de la Consejería en VIH/SIDA}

\section{Resumen}

Estudios nacionales e internacionales indican que a consejería en ETS/sida presenta fragilidades y problemas tales como la carencia de fundamentación teórica o inconsistencias entre bases teóricas y desdoblamientos técnicos. Este estudio examinó contribuciones de uno de los marcos teóricos que influyeron en la construcción de estrategias de consejería en ETS en Brasil, el Abordaje Centrado en la Persona (ACP), de Carl Rogers. Se analizaron las limitaciones de su uso en el ámbito de las ETS/sida, a partir del análisis de documentos producidos por la Organización Mundial de la Salud, el Programa de Sida de Naciones Unidas y el Ministerio de Salud de Brasil. El material documental fue tratado desde el punto de vista interpretativo, cotejando las construcciones conceptuales rogerianas con los componentes del proceso de trabajo recomendado en los documentos, examinándose la consistencia y coherencia internas. Fueron evidenciadas incompatibilidades en relación a: objetivos, foco, resultados esperados y postura del profesional. Tales desacuerdos parecen ser consecuencia de diferencias entre las finalidades originales de la consejería basada en la ACP y aquellas requeridas en las estrategias de prevención de ETS/sida. La confluencia de diversas finalidades confiadas a la consejería en el campo de las ETS/sida configura obstáculos para un uso consciente de la ACP. Se señala la pertinencia del abordaje rogeriano en la consejería como técnica de apoyo en la toma de decisiones y el manejo de situaciones cotidianas, pero se apunta a la necesidad de rever objetivos y procedimientos estandarizados y orientados al cambio de comportamiento y a la vigilancia epidemiológica.

Palabras clave: Síndrome de inmunodeficiencia adquirida, enfermedades de transmisión sexual, modelos teóricos, Abordaje Centrada en la Persona, Carl Rogers, estrategias de prevención.

O termo "aconselhamento" vem sendo utilizado historicamente para uma extensa variedade de atividades e intervenções, relacionadas principalmente ao manejo individualizado de situações, desafios e dilemas da vida cotidiana, à promoção do desenvolvimento humano e ao bem estar pessoal. Desde a década de 1920 até a década de 1950, passou-se a denominar aconselhamento a esta prática de ajuda focalizada e objetiva, de caráter educativo e preventivo que, 
através da descoberta, avaliação, realce e incremento dos recursos internos e interpessoais de indivíduos e grupos, busca contribuir para uma melhor qualidade de vida e uma maior satisfação pessoal. (Whiteley, 1999).

Com o passar dos anos, este tipo de relação de ajuda veio se especializando cada vez mais, acumulando diferentes técnicas e metodologias, princípios e abordagens, baseadas em diferentes concepções do ser humano, do que vem a ser uma relação de ajuda e em variadas compreensões sobre os processos de desenvolvimento da personalidade, de mudança de comportamento e do processo de ensino-aprendizagem.

Apesar de existir certa variação na forma como tem sido definido, o aconselhamento tem sido compreendido entre diferentes autores, como uma tecnologia de ajuda, de cuidado, e como uma prática instrumental que oferece auxílio estruturado e personalizado para o manejo de situações difíceis e de crise que exigem ajustamentos e adaptações, para a solução de problemas específicos e para a tomada de decisões (Corey, 1997; Pattersson \& Eisenberg, 2003; Scheeffer, 1976).

Para isso, o aconselhamento engloba, em termos sintéticos, as seguintes etapas e tarefas: (a) identificação e análise de problemas e circunstâncias específicas da vida; (b) aumento do discernimento, conhecimento e consciência dos diferentes elementos envolvidos nestas situações; (c) avaliação das condições, recursos (pessoais e sociais), estratégias, alianças e obstáculos existentes para manejá-las; (d) definição do potencial de mudança dessas condições e atitudes pessoais; (e) escolha, e experimentação de ações específicas, consideradas factíveis e convenientes para a transformação da realidade em questão (Corey, 1997; Pattersson, 1973; Pattersson \& Eisenberg, 2003; Santos, 1982; Tyler, 1969).

Contribui, portanto, para que o indivíduo tenha mais elementos para se posicionar frente à sua situação de vida, elaborando assim um plano de ação personalizado, contextualizado e satisfatório. Para tanto, esta tecnologia se apoia no estabelecimento de condições favoráveis para que o indivíduo avalie seus problemas $e$ tome decisões. Concentra-se no manejo dos aspectos socioculturais e afetivo-emocionais das situações (World Health Organization [WHO], 1995b).

A prática do aconselhamento vem apresentando, entretanto, imprecisões e ambiguidades, dificultando sobremaneira uma clara demarcação e discriminação de suas fronteiras e de sua específica identidade. Isso se deve, em parte, pelo fato de ter sido constituída, desde suas origens, com certo grau de hibridismo, reunindo saberes tanto do campo da educação como da psicologia e enfocando tanto aspectos cognitivos como afetivos e emocionais (Lewis, 1970; Santos, 1982; Scheeffer, 1976; Whiteley, 1999).

$\mathrm{O}$ aconselhamento também tem sido inserido como uma estratégia para se lidar com a dimensão psicossocial da epidemia de HIV/aids. Inicialmente, na década de 1980, foi utilizado na situação de testagem anti-HIV, como uma abordagem para lidar com a discriminação associada à aids, como espaço para esclarecer e diminuir as barreiras em torno do teste e aumentar a informação da população sobre esta doença e formas de prevenção.Posteriormente, na década de 1990, foi utilizado para manejar os diferentes limites desta mesma terapêutica (diagnóstico tardio, ausência de vacinas, efeitos secundários, dificuldades na adesão ao tratamento).

Ao longo dos anos, como parte da resposta social oferecida internacionalmente para o enfrentamento desta epidemia, o aconselhamento foi sendo associado a uma "porta de entrada" à diversas estratégias de resposta à epidemia, ao acesso às diversas estratégias de resposta à epidemia: oferecimento voluntário e informado da testagem anti-HIV, tratamento precoce dessa doença, interrupção e diminuição da cadeia de infecção, controle da transmissão materno infantil, fornecimento de orientação qualificada, personalizada e contextualizada, e diminuição do estigma, dos preconceitos e demais impactos sociais e pessoais desta epidemia (Joint United Nations Programme on HIV/AIDS [UNAIDS], 2000a; WHO, 1995b).

O mesmo processo ocorreu no Brasil sendo o aconselhamento introduzido no final da década de 1980 (Ministério da Saúde [MS], 1988, 1989, 1993).

Estudos nacionais e internacionais mostram, porém, que os profissionais que realizam 
o aconselhamento possuem distintas compreensões e concepções sobre sua estrutura e objetivos (Centers for Disease Control and Prevention [CDC], 2001) e que existe uma importante variação na forma como ele é executado (Castrucci, Kamb, \& Hunt, 2002; CDC, 2001; Grinstead, 1997; Holtgrave, Reiser, \& Franceisco, 1997; UNAIDS \& WHO, 2000). Aponta-se que, em muitas situações, o aconselhamento é banalizado e visto como um simples repasse de informações ou como uma atividade pré formatada de orientação padronizada em função do perfil de risco, ignorando sua complexidade e especificidade e subestimando a dimensão psicossocial e de cuidado inerentes a esta atividade (Filgueiras \& Deslandes, 1999). Além desses problemas, o aconselhamento é frequentemente confundido com outras práticas de cuidado, tais como ações educativas e orientação individual sobre procedimentos (Dolcini, Canin, Gandelman, \& Skolnik, 2004).

Mesmo os manuais e documentos de referência carecem de uma clara e precisa fundamentação teórica e técnica, apresentando essa atividade como uma "receita pronta", isto é, como um arsenal de conteúdos, orientações gerais e informações técnicas consideradas relevantes que deveriam ser reproduzidos nos atendimentos. Existem, ademais, poucas avaliações sobre a qualidade e efetividade da utilização dessa tecnologia (Sikkema \& Bissett, 1997).

A falta de fundamentação teórica e discussão conceitual mais consistente torna muitas vezes a execução desta atividade bastante dependente da formação anterior de cada aconselhador, de seu interesse e curiosidade intelectual e da sistematização que consegue fazer de sua prática. A prática cotidiana do aconselhamento reclama algum grau de fundamentação teórica, sob pena de perder-se sua eficácia tecnológica, sendo efetuada de forma mecânica ou intuitiva. Além disso, as reflexões teóricas que sustentam esta ação podem fornecer uma base para julgar se todos os elementos necessários à intervenção foram observados, identificando fatores e condições que favorecem e que limitam seu sucesso e aplicabilidade, o que contribui para uma precisa avaliação de quando e como tal tecnologia deve ser utilizada.
A própria noção de "best practices", ou "melhores práticas", desenvolvida pela UNAIDS para avaliar os cuidados médicos, mas já aplicada à atividade de aconselhamento, propõe que as melhores práticas são: aqueles processos ou atividades que incorporam os valores, os princípios e os conceitos das teorias de base; que são consistentes com a evidência científica e que podem desenvolver-se de diferentes maneiras segundo o contexto. Desta forma, para caminhar-se na direção das práticas mais adequadas e consistentes, é necessário clarificar muitos bem os conceitos, os princípios e as opções metodológicas que lhe subjazem (Myers, Worthington, Haubrich, Ryder, \& Calzavara, 2003).

Se a prática do aconselhamento é considerada, mundialmente, tão relevante nas estratégias de resposta à epidemia de HIV/aids, então, caberá nos questionarmos acerca do que está ocorrendo com o aconselhamento no contexto brasileiro. E aceitando que a clareza de seus fundamentos teóricos e sua coerência com as proposições técnicas são pressupostos para a qualidade da aplicação do aconselhamento, um relevante ponto de partida será argüir sobre o quanto essa prática está fundamentada e coerente nas orientações técnicas que balizam a resposta brasileira. Nesse sentido, este artigo pretende analisar a principal referência teórica utilizada nas proposições técnicas do aconselhamento no campo das DST/aids no Brasil - a Abordagem Centrada na Pessoa, de Carl Rogers - identificando tanto os subsídios oferecidos por esta corrente teórica para estruturar as práticas propostas, bem como inconsistências, incoerências e dificuldades da adoção de tal referencial teórico no contexto brasileiro.

\section{Método}

Para proceder a este estudo foram percorridas as seguintes etapas:

1. Levantamento e análise de manuais, documentos normativos e recomendações sobre o aconselhamento em DST/Aids nacionais e internacionais. O corpus documental nacional consiste de todos os manuais e documentos de referência oficiais produzidos entre 1988 e 2011 pela Coordenação Nacional 
de DST/aids/MS e relacionados à prática do Aconselhamento em DST/aids. Quanto aos internacionais, foram selecionados os manuais internacionais citados como referência para a elaboração dos manuais nacionais, aqueles que foram citados na maioria dos artigos sobre aconselhamento em DST/ aids (nacionais e internacionais), e que foram produzidos por organizações internacionais da área - UNAIDS e CDC.

Os manuais e documentos de referência nacionais levantados foram: Manual de Condutas Clínicas (MS, 1988); Manual de Aconselhamento/AIDS (MS, 1989); Normas de Organização e Funcionamento dos Centros de Orientação e Apoio Sorológico (MS, 1993); Aconselhamento em DST/HIV/Aids: Diretrizes e Procedimentos Básicos (MS, 1997); Manual de Treinamento em Aconselhamento em DST, HIV e Aids (MS, 1998); Diretrizes dos Centros de Testagem e Aconselhamento - CTA (MS, 2000); Aconselhamento em DST/HIV para a Atenção Básica (MS, 2004); Oficina de Aconselhamento em DST/HIV para a Atenção Básica (MS, 2005); Relatório do I Encontro Nacional de Avaliação dos COAS (MS, 1994); Relatório do II Encontro Nacional de Avaliação dos COAS (MS, 1996a); Relatório do Seminário de Aconselhamento (MS, 1996b); Relatório de Estudo Nacional sobre a Avaliação das Ações de Aconselhamento em DST/AIDS (MS, 1999).

Os manuais e documentos de referência internacionais analisados foram: Guidelines for Counseling about HIV infection and disease (WHO, 1990); Technical Guidance on HIV Counseling, Testing e Referral: Standards and Guidelines (CDC, 1993); Technical Guidance on HIV Counseling, Testing e Referral: Standards and Guidelines (CDC, 1994); Revised Guidelines for HIV Counseling, Testing and Referral and Revised Recommendations for HIV Screening of Pregnant Women (CDC, 2001); Counseling for HIV/Aids: A Key to Caring (WHO, 1995a); Source Book for HIV/Aids Counseling Training (WHO, 1995b); Voluntary Counseling and Testing (VCT) Technical
Update (UNAIDS, 2000b); Opening up the HIV/Aids Epidemic: Guidance on Encouraging Beneficial Disclosure, Ethical Parther Counseling and Appropriate Use of HIV Case - Reporting (UNAIDS \& WHO, 2000); Tools for Evaluating HIV Voluntary Counseling and Testing (UNAIDS, 2000a); The Impact of Voluntary Counseling and Testing: A Global Review of the Benefits and Challenges (UNAIDS \& WHO, 2001); Increasing Access to HIV Testing and Counseling (WHO, 2002);

2. Identificação dos textos e trechos que se referiam à Abordagem Centrada na Pessoa de Carl Rogers para fundamentar as recomendações propostas;

3. Revisão do quadro conceitual da Abordagem Centrada na Pessoa, baseada no estudo de oito dos doze livros de Rogers, abrangendo desde o início de sua produção até seus últimos escritos. Foram também estudados doze artigos de diferentes períodos de sua vida, que discutem: a prática da psicoterapia e a relação de ajuda; o processo de comunicação interpessoal; o processo de tornar-se pessoa; a prática da ciência e a prática de atendimento clínico; sua visão de educação e de ensino-aprendizagem; e a abordagem de problemas, dificuldades e tensões sócio culturais, políticas e comunitárias. Também foram levantados e analisados doze artigos e um livro escritos por comentadores e críticos do pensamento de Rogers. A seleção e análise do material buscou privilegiar textos que contribuíssem para esclarecer os diversos elementos implicados no estabelecimento de uma relação interpessoal de ajuda efetiva, tal como pretende ser o aconselhamento em DST/aids e que, portanto, discutiam e examinavam: as características, os componentes, as condições e os resultados envolvidos na prática de uma relação de ajuda;

4. Cotejamento e comparação das contribuições oferecidas por esta corrente teórica com as principais recomendações fornecidas pelos manuais e documentos de referência para instruir os profissionais sobre a execução dessa prática. 
Todo o corpus documental foi trabalhado a partir de uma perspectiva compreensivo-interpretativa (Gadamer, 2004). Com a proposta de fazer uma abordagem hermenêutica dos documentos levantados, o plano de análise e investigação desse material partiu da busca de respostas a perguntas e questionamentos considerados importantes para a prática de aconselhamento em DST/aids: características da relação de ajuda, condições para sua execução e sucesso, papel do profissional, resultados esperados, seu formato e seus limites. Ocupou-se, também, de entender, mesmo que de forma limitada, a tradição de pensamento e o contexto de origem de onde parte o pensamento de Rogers e os textos técnicos trabalhados.

Foram assim, delineadas as seguintes categorias de análise: (a) concepção de aconselhamento; (b) objetivos e resultados esperados; (c) papel e atitudes do profissional; (d) papel da pessoa que recebe ajuda. Para cada uma dessas categorias, buscou-se assinalar inicialmente a visão trazida pela teoria rogeriana, pontuando algumas contribuições e limites e, a seguir, cotejou-se tal perspectiva com o proposto nos manuais de DST/aids, identificando possibilidades e dificuldades da aplicação deste referencial teórico dentro desse contexto específico.

\section{Contribuições e Subsídios da Abordagem Centrada na Pessoa para a Prática do Aconselhamento em DSTIAIDS}

\section{Concepção Rogeriana de Aconselha- mento e seu Aproveitamento no Campo das DST/Aids}

Um primeiro aspecto a ser destacado no quadro rogeriano é a centralidade na cena de atendimento, da relação humana e das pessoas implicadas nela. Assim, apesar do aconselhamento poder ser visto como uma tecnologia, ele sempre será, antes de tudo, um relacionamento e um encontro interpessoal e intersubjetivo (Rogers, 2005b). Esta visão traz à tona as subjetividades presentes, ou seja, a dimensão existencial, experiencial e simbólica dessa vivência, desse encontro humano, com seus sentidos, sensações e significados próprios, mostrando o quanto esses fatores são decisivos para o direcionamento, intensidade, qualidade, relevância e efeitos dessa relação para os indivíduos por ela abrangidos (Rogers, 2001a). Sob esta perspectiva, este encontro não pode ser reduzido nem a uma simples conversa nem à estrita aplicação de uma técnica. É um "jeito de ser" e de posicionar-se frente ao outro, é uma vivência em aberto, indeterminada, a ser construída, ainda que carregue uma intencionalidade e uma expectativa prévia de ambos os lados, e possa ser apoiada por saberes técnicos e científicos (Kirschenbaum \& Henderson, 1989).

Deste modo, o aconselhamento não é uma atividade com procedimentos determinados ou um "modo de fazer" genérico, repetitivo e prescritivo. Não é uma técnica ou uma estratégia previamente direcionada e fechada em seus horizontes de atuação, nem mesmo um espaço para fornecimento de orientações, sugestões e conselhos antecipadamente estruturados e estabelecidos. Os conteúdos e procedimentos não existem em si mesmos, não são o guia para a ação, mas precisam "deixar-se" adaptar, e serem modificados e contextualizados a partir das situações, experiências e projetos de vida daquele que recebe o aconselhamento.

Qualquer problema ou assunto concreto não deve ser abordado em si mesmo, de forma fragmentada, mas sim em sua relação com a totalidade da experiência vivida pela pessoa - incluindo aspectos cognitivos, afetivos, sensoriais, sociais, bem como o presente, o passado e o futuro. É a pessoa como um todo, historicamente situada, que vive determinados problemas e situações e que dá a eles determinados significados e valorações, que deve ser acessada e atingida na abordagem dos mesmos. Há um alargamento do horizonte normativo que rege esta prática: o guia para a ação é a totalidade existencial das pessoas envolvidas.

É um relacionamento de ajuda, de proveito e de utilidade para o outro. Mas tal ajuda é vista no sentido de serventia e de interesse, especialmente para a pessoa à qual se pretende ajudar, ou seja, é focada na pessoa do outro, em sua alteridade, e não nos interesses e demandas pessoais 
e sociais do profissional de ajuda ou do contexto social aonde esta situação se desenrola. É uma prática que pretende ajudar outro individuo a ajudar-se (Rogers, 2001a).

Todavia, não é um procedimento a ser feito PARA o outro, mas um fornecimento de condições para que o indivíduo avalie seus problemas e tome decisões. É uma tecnologia de cuidado, que se apoia no estabelecimento de condições favoráveis dentro da própria relação interpessoal e comunicativa e no manejo dos aspectos socioculturais e afetivo-emocionais das situações. É um tipo de relação que, por suas próprias características, pode ser usada pelo outro em seu próprio benefício.

No campo das DST/aids, é interessante notar que a concepção de aconselhamento sofreu algumas modificações na forma como foi definida, principalmente pelos manuais nacionais, desde 1988 até sua última versão direcionada à atenção básica em 2005. Nos manuais de 1988 e 1989, o aconselhamento era concebido e desenhado como uma estratégia e um procedimento diretivo, focado no esclarecimento intelectual, no fornecimento de informações e no provimento de sugestões de comportamento e de ação, previamente estabelecidas pelas políticas públicas, pelos estudos epidemiológicos e conhecimentos existentes sobre prevenção e pelos discursos técnico-científicos das diversas áreas teóricas implicadas (MS, 1988). O manual de 1989 cita, inclusive, que o conteúdo abordado deveria ser padronizado e que deveriam ser utilizadas técnicas uniformes para o desenvolvimento dessa prática, apesar de não especificar que técnicas seriam essas (MS, 1989).

Em um segundo momento, no manual de 1993 (Normas de Organização e Funcionamento dos Centros de Orientação e Apoio Sorológi$c o$ ), o aconselhamento não é visto apenas como um espaço de fornecimento de informações, mas é considerado igualmente uma prática que deve se mostrar efetiva na motivação para mudança de comportamento. Contudo não existe aqui qualquer distinção entre aconselhamento e educação em saúde, e este manual parece associar a mudança de motivação e a capacidade de alterar comportamentos estritamente ao convencimento intelectual e apropriação cognitiva sobre os riscos de infecção pelo HIV e, para isso, ao acesso a informações técnico-científicas acuradas. Não direciona e nem instrui sobre como deveria ser uma abordagem mais personalizada, ou como poderia ser realizado o manejo de aspectos afetivo-emocionais (MS, 1993).

Aconselhamento é um processo que pode auxiliar o indivíduo a entender melhor e lidar com seus problemas, conviver com seu ambiente social e, quando for o caso, motivar para a mudança de comportamento. É desenvolvido através de informação e educação direta e pessoal e tem papel crítico na prevenção e controle da SIDA/AIDS. (MS, 1988, p. 13)

Em um terceiro momento, a concepção de aconselhamento no campo da aids vai se ampliando e se remodelando para uma noção de cuidado. Esta nova concepção é apresentada a partir do Manual de "Aconselhamento em DST/ HIV/Aids - Diretrizes e Procedimentos Básicos" de 1997, do Manual de "Diretrizes do Centro de Testagem e Aconselhamento-CTA" (MS, 2000), e depois reforçada pelo Manual de "Aconselhamento em DST/HIV/Aids para a Atenção Básica" (MS, 2004). Nesses materiais, ela se mostra muito mais claramente baseada e influenciada pela Abordagem Centrada na Pessoa, de Carl Rogers.

Nesses últimos manuais, o aconselhamento não é visto como um procedimento estruturado $\mathrm{e}$ fechado ou como uma técnica, mas sim como um diálogo; uma relação comunicativa baseada em valores e atitudes que visam proporcionar condições favoráveis e um ambiente propício para que o próprio indivíduo avalie seus riscos, dificuldades e contexto, tome decisões e encontre maneiras satisfatórias de enfrentar os problemas. É definido como um processo individualizado e centrado no cliente, e busca resgatar sua integralidade enquanto pessoa (MS, 1997, 2004).

Nessa nova concepção, o aconselhamento é definido como uma ação continuada (processo), centrado não em um problema, ou em um conteúdo específico a ser passado, ou mesmo em um rol de informações a serem coletadas; mas sim, na pessoa que busca ajuda - sua demanda, motivos de vinda ao serviço, percepções, medos, 
dúvidas, questões, interesses e dificuldades concretas. Não é visto como um procedimento a ser feito para o outro, ou como a indução de uma ação específica a ser executada pelo outro, mas apenas com uma relação que consiga propiciar condições para que o indivíduo avalie seus problemas, situação e riscos pessoais, tomando decisões a respeito. Dentro dessa perspectiva, não é o profissional que avalia os riscos para o outro, ou que explora os problemas através de um questionário específico, ou dá as soluções mais adequadas. Ele apenas propicia condições para que o indivíduo possa fazer isso.

Entendemos como aconselhamento um processo de escuta ativa, individualizado e centrado no cliente. Pressupõe a capacidade de estabelecer uma relação de confiança entre os interlocutores, visando ao resgate de recursos internos do cliente, para que ele mesmo tenha possibilidade de reconhecer-se como sujeito de sua própria saúde e transformação. (MS, 1997, p. 11)

É um diálogo, baseado em uma relação de confiança que visa proporcionar à pessoa condições para que avalie seus próprios riscos, tome decisões próprias e encontre maneiras de enfrentar seus problemas relacionados às DST/HIV/AIDS (MS, 2004, p. 7).

Nos manuais internacionais estudados percebe-se uma maior regularidade na forma como o aconselhamento é concebido. Desde o início da década de 90 , estes manuais possuem uma influência clara e marcante da abordagem rogeriana e, portanto, uma maior abertura para a construção de uma relação não programada, focada na dimensão afetivo-emocional e social das vivências dos clientes e nos significados dados a elas, por cada indivíduo. Tanto o CDC como a UNAIDS propõem desde então um modelo interativo de aconselhamento, centrado na pessoa que solicita ajuda, distinguindo-o de um atendimento individualizado que oferece mensagens informativas padronizadas de avaliação e redução de risco (CDC, 2001; WHO, 1995b).

Estes manuais diferenciam ainda a ação de aconselhamento da ação educativa, indicando que, no aconselhamento, a comunicação é personalizada, confidencial; visa provocar mudanças relevantes na vida pessoal e ajudar na solução de problemas individuais; nele a dimensão informacional está sempre subordinada e relacionada ao manejo de aspectos socioculturais, afetivos e emocionais do diagnóstico, prevenção e tratamento. A informação serve, portanto, a um propósito individual e deve estar articulada com a experiência de vida e necessidades pessoais de cada indivíduo (CDC, 2001; WHO, 1995a, 1995b).

Da mesma forma, há uma maior explanação e discussão sobre as posturas e atitudes a serem desenvolvidas pelo profissional em diferentes contextos.

A despeito da importante mudança de perspectiva na concepção e conceituação do aconselhamento nos manuais brasileiros no decorrer do tempo, percebe-se que os próprios manuais não estruturam os seus objetivos, os procedimentos e ações propostas com base nessa definição que apresentam.

\section{Objetivos e Resultados Esperados para o Aconselhamento}

A Abordagem Centrada na Pessoa (ACP) propõe objetivos para a relação de ajuda efetivamente articulados com a pessoa do outro. $\mathrm{O}$ aconselhamento deixa de se fixar em objetivos fechados e pré-concebidos, para se concentrar na criação de condições favoráveis para que o próprio indivíduo analise e compreenda sua realidade, estabeleça suas metas em relação a seu momento de vida e mobilize recursos para atingi-las. (Rogers, 2001b, 2005a). Assim, os objetivos devem ser sempre estruturados, organizados junto com o outro, ou seja, devem ser construídos na relação. O indivíduo que pede ajuda sempre deve participar da delimitação do que será abordado e da meta a ser atingida.

Os objetivos do aconselhamento aí proposto fundamentam-se na convicção de que cada pessoa tem o direito de ser corresponsável pela construção do seu atendimento, e de escolher seus próprios fins na vida, mesmo que esses sejam divergentes daqueles que o profissional teria escolhido para ele. Além disso, admite-se a impossibilidade, a inutilidade, a ineficiência, a arbitrariedade e a prepotência de se tentar gerir e conduzir diferentes aspectos da vida de outrem, 
ainda que seja com o consentimento dele mesmo. Deixa, assim, o atendimento mais flexível ao valorizar e utilizar as demandas e a experiência vivida por cada pessoa diante de determinada situação, como guia para a construção de cada sessão.

Em relação aos resultados esperados com a tecnologia do aconselhamento, a concepção rogeriana de relação de ajuda, sugere resultados que sejam mais realistas, especificos, personalizados, acordados e vinculados à experiência individual, ou seja, uma solução que seja boa para determinado indivíduo, em um determinado momento histórico, em determinado contexto e não genéricos e concentrados em uma opção de ação pré-configurada - um produto ou resultado bom para todos. Os resultados esperados com o aconselhamento, portanto, não podem ser estáticos e fixos, mas construídos com o indivíduo; são inéditos e variáveis, o que possibilita a emergência de soluções inovadoras, originais e articuladas com o contexto social, cultural e com as condições afetivo-emocionais do indivíduo. Isso só aumenta as possibilidades de manejar e superar os obstáculos da prevenção e da assistência.

Tais resultados, nesta visão de relação de ajuda, são também referentes à pessoa em sua integralidade, isto é, são mudanças relativas principalmente ao modo como o indivíduo percebe e posiciona-se com relação a si mesmo e à sua realidade. Estas mudanças relacionam-se a uma ampliação do campo perceptivo e de conhecimento sobre determinada situação/problema e a um aumento do controle e do domínio do indivíduo sobre determinada condição, área ou situação da vida - e sobre as oportunidades e recursos existentes.

Os principais resultados alcançados pelos indivíduos que participaram de processos de ajuda foram descritos por Rogers (1981, 2001a) da seguinte maneira: (a) maior abertura à própria experiência, ou seja, maior disponibilidade e capacidade de acessar, enxergar, aceitar e compreender os diferentes elementos objetivos e subjetivos presentes em uma dada situação; (b) visão mais realista de si e de sua realidade; (c) menor rigidez e maior flexibilidade para enxergar e manejar a realidade; (d) maior abertura a mudanças de atitudes e a transformações em sua própria vida; (e) maior autodireção, autonomia e responsabilidade por si mesmo; (f) visão e expectativas mais realistas das pessoas à sua volta.

Esta visão de resultados esperados identificada na abordagem rogeriana amplia consideravelmente o horizonte normativo do aconselhamento, tornando a expectativa em relação ao atendimento mais abrangente, aberta e, ao mesmo tempo, mais dependente da singularidade e da disponibilidade individual. Insere-se ainda nessa perspectiva, o compromisso do profissional não apenas com um problema determinado, uma política, ou com a superação de um mal coletivo, ainda que esse norte possa participar do atendimento desenvolvido, mas introduz-se também, e principalmente, um compromisso com a felicidade humana, com o que Rogers chama de "vida boa" (Rogers, 2001a).

Em relação aos seus objetivos e resultados, este estudo encontrou algumas contradições, oposições e contrastes entre a racionalidade da Abordagem Centrada na Pessoa e a racionalidade do aconselhamento em DST/aids tal como delineado nos manuais nacionais e internacionais levantados.

Uma primeira oposição está relacionada ao fato de que o aconselhamento proposto pelos manuais tem sua estrutura operacional (o como fazer) voltada a um caminho mais diretivo, fechado, coordenado por metas da saúde coletiva. $\mathrm{O}$ aconselhamento em DST/aids, principalmente a partir de 1997, apesar de ser referido como uma relação de ajuda centrada no individuo, acaba por definir objetivos que não são totalmente consoantes com essa concepção.

Em todos os manuais nacionais e internacionais, ainda que de formas distintas ${ }^{2}$, os objetivos do aconselhamento em DST/AIDS definem

2 Os manuais internacionais ressaltam a importância da flexibilidade nos objetivos propostos para cada sessão de aconselhamento, apontam para o equivoco de usar a sessão para coleta de dados para o serviço ou para o fornecimento de informação padronizada, advertem contra a tendência de "encaixar" as pessoas em uma mesma mensagem de prevenção, desafiam os profissionais a acessarem o contexto e a perspectiva afetivoemocional e sócio cultural dos indivíduos (CDC, 2001; WHO, 1995b). 
e misturam metas e preocupações comprometidas com o plano individual, mais abertas e focadas na singularidade e dinamismo da pessoa em questão, e metas coletivas e sociais, conformadas por um ideal de bem estar social e com uma visão global de vida saudável, muitas vezes distantes da realidade individual. Ambas as metas pretendem ser igualmente atingidas pelo aconselhamento e dirigem-se simultaneamente ao indivíduo em questão, sugerindo que o mesmo seja abordado tanto em uma perspectiva normalizadora e genérica sobre o seu comportamento, como em uma perspectiva fortalecedora e reconhecedora de sua autonomia e singularidade.

Dessa forma, metas mais personalizadas e indeterminadas são propostas, tais como: $a$ redução do nivel individual de estresse; a reflexão e auto-compreensão pessoal que possibilite a percepção dos próprios riscos e revisão de seu posicionamento frente a eles; o estabelecimento de condições favoráveis para que o individuo identifique e enfrente situações adversas e possa tomar decisões; o empoderamento e fortalecimento da autonomia do individuo; o suporte e expressão emocional para enfretamento de dificuldades e assuntos difíceis; e a promoção da autoconfiança individual. Estes objetivos, contudo, convivem com outros mais gerais, coletivos e pré-configurados, tais como: a quebra da cadeia de transmissão das DST e HIV; adoção de práticas consideradas seguras ou mudança de comportamento de risco; comunicação e tratamento de parceiros; adesão ao tratamento; $e$ o fornecimento de informações atualizadas sobre as DST/HIV/aids (MS, 1997; WHO, 1995a, 1995b).

Esses dois focos de ação traduzem compromissos distintos, bem como configuram-se como duas racionalidades diversas na construção e condução do atendimento, a do suporte individual e o compromisso com procedimentos e demandas epidemiológico-sanitárias, ou seja, com as políticas universais de prevenção e assistência às DST/aids. Deste modo, como também nos advertem outros autores que analisam o aconselhamento em DST/Aids, apesar de haver um espaço aberto ao diálogo, existe uma certa rigidez neste presumido "diálogo", na medida em que os projetos pessoais são submetidos à racionalidade das ações públicas (Souza \& Czeresnia, 2007).

Nas situações em que o objetivo principal é a execução de uma política, a pessoa, em suas diferentes dimensões, com suas necessidades, desejos e projetos de vida, tende a ficar em segundo plano. Com esta pauta e agenda coletivas, e este discurso de caráter mais universal e normativo, fica muito mais difícil incorporar a proposta de uma ação focada na avaliação particular de cada contexto e realidade individual. A ênfase em protocolos, conhecimentos e procedimentos padronizados caminha frequentemente no sentido inverso da postura necessária para acessar experiências, percepções e a compreensão do indivíduo em cada uma das situações. Promover e incentivar um determinado comportamento e uma ação pré-fixada aponta em uma direção distinta de ajudar o indivíduo a compreender-se e tomar livremente decisões pessoais.

\section{Papel e Postura do Profissional}

Segundo Rogers, um dos elementos centrais para a construção de uma prática de ajuda eficaz e resolutiva é a própria atitude e postura assumida pelo profissional neste atendimento. A visão que o profissional tem de seu papel nesta relação determinará sua condução do atendimento, suas prioridades, as técnicas utilizadas, sua expectativa em relação ao comportamento do indivíduo a quem quer ajudar e o espaço que concede a ele nessa relação (Rogers, 1981).

Além disso, a construção de uma relação de ajuda nesta perspectiva se baseia fundamentalmente no estabelecimento de condições interpessoais e intersubjetivas favoráveis à auto-percepção, auto-exploração, auto-conscientização e auto-determinação do sujeito em relação à sua realidade.

Um primeiro aspecto digno de nota em relação à postura e atitude do profissional proposta por Rogers é a sua disponibilidade para a auto-restrição, ou seja, sua deliberada abstenção de ser o centro e o elemento norteador da ação, bem como de utilizar o poder conferido por sua própria formação e papel profissional, para constranger o outro em relação a determinado comportamento ou opinião (Rogers, 1981). 
Sendo assim, apesar do profissional sempre trazer uma intencionalidade e uma expectativa própria - como diminuir risco de infecção, melhorar a qualidade de vida ou mostrar a relevância e a serventia de determinadas estratégias preventivas - e ainda que possa, em algumas situações, expor essa intencionalidade e expectativa ao outro, a ação proposta por Rogers não se assenta em uma agir estratégico (uma agir sobre o outro). Aproxima-se bem mais de um agir comunicativo (um agir com o outro), que busca acessar e entender as razões e motivos do outro, para depois articular perspectivas e possibilidades de encaminhamento que façam sentido dentro da totalidade de existência desse outro. ${ }^{3}$

Esta perspectiva proposta por Rogers traz para a cena um novo movimento e posicionamento frente às ações preventivas. Qualquer ação de prevenção e cuidado discutida no aconselhamento necessita estar articulada e permeável às circunstâncias de vida, aos valores e necessidades consideradas importantes por esse outro.

No mesmo sentido, Ayres (2004), quando discute as implicações do repensar e do reconstruir as praticas de saúde, de forma a buscar o desenvolvimento de ações que possam ir além da "mera reprodutibilidade técnica", sugere que o profissional deve estar aberto a soluções preventivas e ações de cuidado mais singulares e heterodoxas, que fogem de um discurso pré-modelado, do tipo: "todos usarem preservativo, sempre, em todas as relações sexuais". Deve poder usar a escuta acurada e a criatividade conjunta para ajudar o indivíduo a construir, aos pou-

\footnotetext{
No agir estratégico, segundo Habermas, a linguagem aparece tão somente como meio de transmissão de informações, de convencimento e persuasão, o efeito de coordenação da ação ocorre por meio de influências recíprocas em que os atores perseguem fins. A interação se assenta em convicções monológicas e não consegue estabelecer um vínculo de reciprocidades que caracteriza a possibilidade de um acordo e entendimento mútuo. Já na ação comunicativa, a linguagem aparece como geradora de entendimento, fonte de integração social. Buscase conhecer e compreender as razões do outro, busca-se o entendimento sobre uma dada situação (Boufleuer, 2001).
}

cos, soluções viáveis e que façam sentido dentro de sua realidade, mesmo que seja uma solução inesperada e distinta da usual.

Outro aspecto relevante identificado nesta abordagem teórica envolve não iniciar a relação de ajuda com um olhar pré-definido sobre o outro, o que significa não enquadrar as pessoas atendidas em nenhuma apreciação, classificação ou definição fixa. Isso implica em não deixar que o passado ou presente das mesmas, que determinado diagnóstico, que análises sócio-comportamentais prévias de coletividades específicas, ou que determinado contexto limitem a capacidade do profissional de ouvir e compreendera singularidade de cada sujeito e dos contextos individuais, ou o impeçam de acessar, a partir do dialogo intersubjetivo, o que o outro está realmente experimentando e trazendo para a relação. Propõe, desta forma, que não se leve os sentidos prontos, definidos e construídos e que se esteja aberto a novas, improváveis e até surpreendentes formas de entender e enfrentar os assuntos.

Isto significa não encarcerar o outro em uma categoria nosológica particular, ou um especifico grupo social, reduzindo-o, por exemplo, ou a um portador de uma infecção, a um membro de uma população vulnerável, ou a um portador de um comportamento de risco. Implica em enxergar o outro como um ser dinâmico, em constante transformação, um sujeito que se constrói a todo instante em seus contatos com o mundo, uma "não mesmidade" (Ayres, 2001).

Rogers sempre se pronunciou contra qualquer tipo de diagnóstico bio-psico-social do indivíduo que o enquadrasse em alguma tipologia genérica. Não se deve, portanto, transpor sem críticas para o plano individual características comportamentais e sócio-culturais de coletividades e grupos. A análise do indivíduo é singular e transitória, e muda a cada vez que nos encontramos com a mesma pessoa. Isto exige uma postura de abertura ao novo, de não classificação (Rogers, 2001a).

Deixar o outro tornar-se e estar em constante mudança, não encarcerá-lo em uma apreciação, classificação, ou definição fixa específica, cristalizada em algum aspecto de seu presente ou passado (Rogers, 2001a, p. 65). A fim de não enquadrar o outro, e com o 
intuito de permitir que o cliente sinta-se seguro e livre para melhor explorar e compreender sua experiência presente, Rogers mostra o quanto é salutar, inclusive para o profissional, ter um posicionamento que restrinja ao máximo a inerente e natural necessidade humana de classificar e pré enquadrar os fatos. Considera, a partir de seus estudos sobre as relações humanas e os processos comunicativos, que uma das maiores barreiras à compreensão mútua e à comunicação interpessoal é a tendência humana de pré organizar a realidade, sempre julgando e valorando os fatos positivamente e negativamente (o que traz um sentimento de segurança, controle e domínio da situação), sem permitir-se enxergar cuidadosamente a realidade sob outros aspectos e perspectivas (Rogers, 2001a, 2001b).

A maior barreira à comunicação interpessoal é a nossa tendência muito natural a julgar, avaliar, aprovar ou desaprovar as afirmações de outra pessoa ou de outro grupo, analisando-as a partir de nosso próprio quadro de referência, sem entender seu sentido ou significado para o outro. (Rogers, 2001a, p. 382)

Outra característica importante da postura do profissional dentro da concepção rogeriana de atendimento é o necessário envolvimento, implicação, disponibilidade e interesse do profissional na pessoa do outro. Isto implica na existência de uma determinada disposição afetiva no relacionamento que facilita o estabelecimento dessa relação interpessoal. Mesmo porque, esta ação não é uma tarefa mecânica, mas uma vivência e uma experiência racional e afetivamente motivadas (Rogers, 2001b).

O profissional faz uso, no atendimento, não apenas de seus conhecimentos especializados (de uma racionalidade pré-orientada e dirigida), e nem se apoia na execução rígida de uma atribuição estipulada ou na preservação de uma imagem inviolável. Ele deve estar aberto para fazer uso da totalidade de elementos presentes em sua personalidade na leitura da situação, e disposto a descobrir e construir em conjunto com o outro, os sentidos e os significados possíveis na relação.

Nesse sentido, o profissional não somente aproxima sua escuta do outro, mas aproxima igualmente a escuta de si mesmo diante deste outro, deixando-se "ser tocado" por este outro, e identificando o impacto que a presença do outro causa nele mesmo. Como nos afirma Ayres (2004), quando discute a possibilidade de maior autenticidade e efetividade no encontro terapêutico, este tipo de disposição provoca uma infle$x \tilde{a} o$ no tradicional formato do atendimento, e privilegia a escuta acurada e a dimensão dialógica do encontro: o diálogo do profissional com a pessoa que busca ajuda, desta pessoa consigo mesma e do profissional consigo mesmo.

Além dessa abertura, disponibilidade e receptividade para com o outro, Rogers destaca a importância do reconhecimento do outro em sua integralidade, em suas diferenças, e em suas ambiguidades, isto é do reconhecimento dos diferentes tipos de vivências, conteúdos e valores individuais. Isso implica em aceitar como legítimos todas as reações, sentimentos e pensamentos do sujeito que busca ajuda. Dessa forma, todos os tipos de vivências e conteúdos (agradáveis e desagradáveis, construtivos e destrutivos, interessantes ou desinteressantes, claros e confusos) devem ter espaço na relação. A pessoa em aconselhamento deve ter sua existência aceita por inteiro, tal como verdadeiramente é, ou como se apresenta no momento, com suas ambiguidades, contradições e idiossincrasias (Rogers, 2001a).

Desse modo, não se procura adequar, alterar, negar, distorcer ou minimizar a vivência e o sentimento trazido pelo outro, dando a eles um sentido, uma explicação e interpretação prévias e prontas, de forma a ficarem mais palatáveis e menos incômodos (como por ex: "você não pode estar se sentido tão abandonado assim, apesar de não conseguir falar com sua esposa, porque você mesmo disse que ainda tem amigos", ou "você não precisa ter tanto medo de fazer esse exame, pois é sempre melhor saber sua situação sorológica de forma a poder se cuidar e minimizar as consequências, o quanto antes", ou "porque você se sente tão mal e incomodado de usar preservativo? Tenho certeza de que você pode se acostumar com ele, você só precisa tentar"). Deixa-se que a própria exploração da experiência revele seu significado. Assim, permite-se que o ódio seja ódio, a vergonha seja vergonha, e o sentimento de impotência e destruição sejam eles 
mesmos, e se busca nessa experiência os seus próprios motivos, consequências, possibilidades de enfrentamento e interpretações dados a ela.

Esta condição implica que o terapeuta esteja realmente pronto a aceitar o cliente, seja o que for que o cliente esteja sentindo, e vivendo no momento: cólera, confusão, medo, desgosto, orgulho, desânimo, irritação, ironia, desinteresse, coragem, admiração. Significa que o terapeuta se preocupa com o individuo de forma não possessiva e autocentrada, que o aprecia mais na sua totalidade do que de uma forma condicional, que não se contenta com aceitar, simplesmente, seu cliente quando este segue determinados caminhos e desaprová-lo quando segue outros. (Rogers, 2001a, p. 72)

Essa atmosfera de respeito, reconhecimento e abertura às diferentes facetas da existência humana do outro diminui o juízo moralista e cria um ambiente mais protegido, livre e confiável, que facilita a autoconfrontação, a possibilidade de autocrítica e revisão de atitudes. Tal atitude de aceitação não é mecânica ou ensinada, mas é uma disposição que pode ser experimentada e aprendida e que não ocorre em todos os momentos, mas, segundo Rogers, é uma disposição extremamente facilitadora para que cada pessoa sinta-se segura e motivada a explorar melhor a natureza e contornos de seu problema.

Para conseguir fazer isso, o profissional deve aceitar do outro qualquer tipo de experiência vivida (raiva, insegurança, desprezo, descrédito, ansiedade), sem sentir-se ameaçado, frustrado, cobrado e irritado como profissional. Precisa de uma certa humildade e percepção de limites (abrir mão de uma postura onipotente e controladora), um certo fortalecimento, aceitação e consciência da própria identidade pessoal, distinguindo-a da do individuo à sua frente, de forma a não imaginar que a escolha do outro depende estritamente das suas próprias reações, desejos e características pessoais.

Poderei ser suficientemente forte como pessoa, para ser independente do outro e deixar que o outro seja independente de mim? Serei capaz de respeitar corajosamente meus próprios pensamentos e sentimentos, assim como os da outra pessoa? Serei bastan- te forte na minha independência para não ficar deprimido com sua depressão, assustado com seu medo ou envolvido em sua dependência? O meu eu interior será suficientemente forte para sentir que eu não sou nem destruído por sua cólera e medo, nem absorvido por sua necessidade de dependência e de respostas rápidas, nem escravizado por seu afeto, mas que existo independentemente das reações do outro? (Rogers, 2001a, p. 61)

Uma ultima condição, considerada por Rogers como absolutamente central e indispensável a uma relação de ajuda é a postura de escuta e compreensão empática. A compreensão empática é, em primeiro lugar, uma atitude de aproximação deliberada do marco de referência interno do outro, ou seja, um acercamento da síntese dinâmica e pessoal que o indivíduo faz do horizonte normativo que o norteia (valores, tradições, crenças, suposições, regras e normas sociais), de forma a entender melhor as diferentes facetas existentes no campo perceptual do individuo (significados e valores atribuídos), tal como ele o comunica (Rogers, 2001a, 2001b, 2005b).

Em segundo momento, a atitude de compreensão empática envolve devolver e comunicar para a pessoa que busca ajuda, tudo o que foi percebido e compreendido pelo profissional em sua atitude de examinar e perscrutar os significados pessoais dados às situações específicas da vida, de forma a ampliar e clarificar a percepção do cliente, a respeito de si mesmo.

Em terceiro momento a compreensão empática implica em checar e avaliar com cada pessoa a precisão e a exatidão da leitura que o profissional fez das vivências da mesma, sempre reformulando e se certificando da validade e legitimidade de tais interpretações a partir das respostas (confirmações ou discordâncias) obtidas com ele.

Essa atitude de aproximação deliberada do marco de referência do outro não é intuitiva e imediata, mas mediada pela comunicação, isto é, pela exposição verbal, explicação e julgamento que o próprio indivíduo faz de suas vivências. Assim, apesar da experiência subjetiva ser uma atividade individual, a compreensão da mesma 
é uma atividade comunicativa. Os sentidos e significados fornecidos são inevitável e constantemente construídos e expressos por meio da linguagem em ato. Há, portanto, sempre uma intersubjetividade que tem de ser suposta, pois existe uma comunicação e uma reconstrução de sentidos.

Rogers ponderou que só era possível alcançar o marco de referência do outro, primeiro, porque ele pode ser comunicado linguisticamente e, segundo, porque existe um substrato de experiências e vivências comuns - que para Rogers estão relacionadas principalmente à experiência do humano, pois ele não se concentra no quanto esse substrato é construído pela cultura (Rogers, 2001b).

É, pois, pela linguagem que chegamos ao outro. Para isso o profissional deve questionar o outro sobre os significados e pesos que são dados aos fatos, contextos e a cada situação e cena relatada. A essência deste tipo de relação de ajuda está na autocompreensão mútua das razões e significados, e não no convencimento; ou seja, está no reconhecimento das motivações, significados e consequências de cada uma das questões e situações expostas pelo cliente.

Os manuais internacionais de aconselhamento em DST/aids investigados, e especialmente o "Source Book for HIV/AIDS Counseling Training" (WHO, 1995b), mostram uma preocupação maior que os nacionais em qualificar as posturas dos profissionais e o manejo do aconselhamento, apresentam de forma muito mais aprofundada valores, técnicas e posturas que devem ser desenvolvidos nesta ação, e inclusive discutem características, contornos e especificidades da comunicação interpessoal como elementos fundamentais para essa ação: postura de buscar a interpretação pessoal dos indivíduos sobre os problemas apresentados; encorajar e facilitar a expressão de sentimentos; reconhecer e distinguir as várias emoções e percepções experienciadas; ajudar os indivíduos a melhor identificarem e delimitarem sua demanda; ajudá-los a explorar as crenças e significados sobre os assuntos em discussão; aceitar e reconhecer como válidas as diferenças nas escolhas, soluções e valores individuais; mostrar as relações entre as atitudes e posturas do individuo e suas consequências no ambiente e para si próprio; confrontar o indivíduo com as inconsistências em sua história, comportamento ou discurso; dar a oportunidade ao indivíduo de redimensionar suas dificuldades, sentimentos e conhecimentos; entre outras (WHO, 1995a, 1995b).

Os manuais nacionais de aconselhamento, especialmente o documento que foi publicado em 1997 e reeditado inúmeras vezes (MS, 1997), não se debruçam sobre o manejo do aconselhamento, não discutem as condições adequadas para sua execução, nem discorrem sobre posturas, atitudes dos profissionais e formas de condução. Não existe nestes manuais nenhum item que discorra e analise habilidades, posturas e técnicas de manejo desta relação interpessoal. Não fornecem, portanto, os elementos necessários para a qualificação e aprofundamento da abordagem interpessoal e manejo técnico desta atividade. Centram-se em sugerir procedimentos a serem executados, mas não aprofundam sobre o significado e a operacionalização dos mesmos ajudar o cliente a avaliar e perceber seus riscos; facilitar a expressão de sentimentos; contribuir para a elaboração de um plano viável de redução de riscos, etc. Também concentram-se em sugerir sugerem conteúdos a serem abordados - informações sobre DST, informações sobre o teste e janela imunológica, etc. Isso propicia uma atuação mais mecânica, padronizada e formatada, ou uma atuação mais intuitiva desta prática.

Em pesquisa realizada em 1995 pela Coordenação Nacional de DST/aids, sobre avaliação das ações de aconselhamento realizadas em diferentes serviços de DST/Aids (Filgueiras \& Deslandes, 1999), entre os principais problemas encontrados estavam: postura de distanciamento em relação às expectativas e vivências do usuário; insegurança em se lidar com situações inesperadas; sensação de despreparo para o manejo de aspectos afetivo-emocionais; postura de "perguntador", sendo que as respostas do usuário não serviam como elementos para o diálogo; repetição de preceitos normativos para a prevenção; priorização de um roteiro perdendo diversas oportunidades para a reflexão de riscos e atitudes individuais. 
No entanto, como é possível personalizar e contextualizar as informações oferecidas e ajudar a pensar estratégias e escolhas que dialoguem com a vivência que o indivíduo tem de seu contexto ou que se ajustem e se articulem com seu projeto de vida, se há pouco espaço para acessar e compreender a dinâmica individual?

\section{Considerações Finais}

\section{Caminhos para a Superação dos Impasses Identificados}

Um primeiro impasse identificado neste estudo refere-se, como vimos, ao fato de que o aconselhamento proposto pelos manuais de aconselhamento existentes no Brasil tem sua estrutura conceitual, valorativa e ideológica inspirada na Abordagem Centrada na Pessoa (a natureza desse trabalho, em nome do que fazer, para que e para quem fazer); mas sua estrutura operacional (como fazer) caminha em outra direção (mais diretiva, fechada e coordenada por metas da saúde coletiva).

Desse modo, a técnica proposta para o aconselhamento em DST/aids acaba tendo uma configuração confusa, fazendo com que a prática efetiva do aconselhamento possa oscilar ora em uma direção, ora em outra, dependendo do perfil, do interesse e da disponibilidade do profissional. O discurso do coletivo, pautado no saber epidemiológico, preventivo e médico-sanitário (com sua urgência em controlar a epidemia e combater o mais precocemente possível todas as possibilidades de risco e infecção), no qual os propósitos são abrangentes, genéricos e uniformes e os problemas e soluções são mais homogêneos e estruturados, sempre precisará de uma mudança de perspectiva ao ser transposto para o plano individual.

Importa ressaltar, que estes dois modos de aproximação da realidade (foco em metas coletivas ou em metas individuais), assim como as ações deles resultantes, são ambos relevantes e indispensáveis para o campo da saúde e para o controle da epidemia. Contudo, talvez eles não precisem ser todos atingidos e resolvidos em uma mesma prática específica. No aconselhamento pode-se e deve-se responder a demandas e questionamentos mais macro e gerais, mas sempre no nível do micro e do particular. Este particular, não é único, coeso e uniforme, mas altamente multifacetado, diversificado, dinâmico e inconstante. Os protocolos de prevenção e assistência, ainda que úteis e relevantes, não são suficientes para acessar a diversidade dessa realidade. Frequentemente é necessário que sejam readequados e adaptados às condições e circunstâncias individuais, assim como acordados intersubjetivamente.

A fim de tentar buscar algumas possibilidades de superação para os possíveis impasses e fragilidades identificados na prática do aconselhamento em DST/AIDS a partir deste estudo, e para fazer um uso consistente de alguns subsídios identificados na Abordagem Centrada na Pessoa, é imperioso notar que nem tudo deve ser resolvido no aconselhamento. $\mathrm{O}$ aconselhamento nunca deve ser visto como uma ação isolada, mas deve sempre estar inserido em uma estratégia mais ampla de prevenção e assistência, aonde se somam outros tipos de intervenção (individual e coletiva) que atinjam os indivíduos e grupos sociais de formas diferentes. As estratégias devem ser tanto globais como particulares e as respostas e soluções devem ser tanto comunitárias como individuais.

Para garantir uma oferta inteligente e coerente do aconselhamento nos diferentes espaços aonde ele é utilizado é indispensável que todos os profissionais que fazem uso desta tecnologia de ajuda compreendam a natureza, as especificidades e a finalidade da mesma, a fim de saber quando e como bem utilizá-la e, portanto, saber diferenciá-la de outras ações do serviço (preenchimento de fichas e protocolos, entrega de resultado, atividades educativas coletivas, acolhimento etc.).

É preciso ainda lembrar que o aconselhamento é uma prática que, desde sua origem, tem trabalhado no âmbito da realidade e do universo individual e não no âmbito do universo do coletivo. Sempre envolve a possibilidade de o indivíduo enxergar, avaliar, expressar-se e posicionar-se sobre sua própria realidade. É, portanto, pela sua própria natureza e características, uma estratégia personalizada e particularizada, que 
busca abordar qualquer situação específica sempre em relação com a totalidade da existência do indivíduo, e não uma ajuda genérica, pronta e pré-configurada.

Os manuais da Organização Mundial de Saúde (WHO, 1995a) deixam claro que a característica maior do aconselhamento é ser uma ação dirigida especialmente para o manejo dos aspectos sócio culturais e afetivo-emocionais do diagnóstico, prevenção e tratamento das DST/ HIV/aids (WHO, 1995a). Há, portanto, nessa prática, uma grande necessidade de habilidades interpessoais, habilidades de escuta e comunicação, e habilidades para acessar e manejar emoções, sensações e significações particulares, e não apenas o domínio de informações técnico-científicas. Deve-se, assim, aproveitar a riqueza e as possibilidades que esse tipo de espaço restrito ao campo interpessoal oferece.

Dentro dessa perspectiva, este estudo incita-nos a qualificar o exercício do aconselhamento, para que essa atividade não seja uma ação burocratizada, rotineirizada, padronizada, "igual pra todos". Deve-se reforçar a proposição de que seja incorporada às estratégias de resposta à epidemia de aids como uma tecnologia de ajuda às pessoas, que favoreça o aumento de sua percepção sobre a questão do risco, infecção ou adoecimento, e as potencialize para realizar mudanças convenientes e relevantes na sua própria vida.

Para isso seria necessário, contudo, que o aconselhamento deixasse de ser um espaço obrigatório e passasse a ser uma atividade voluntária, oferecida de forma inteligente, compreensível, acessível e cuidadosa, a todos os indivíduos que necessitassem e se interessassem por esse tipo de apoio.

Nesse mesmo sentido o aconselhamento precisaria deixar de ter sob seu encargo a execução de procedimentos, a comunicação de conteúdos específicos ou a coleta de informações sobre perfis de risco.

Por fim, mas não menos relevante, cabe acentuar que tal mudança reclamaria também uma atenção especial em relação aos profissionais responsáveis por sua execução, com uma formação mais consistente com o desenvolvimento de atitudes e posturas voltadas para a co- municação e a escuta (não moralista) do outro, bem como um espaço de supervisão e acompanhamento necessários para o bem-estar do profissional e a qualidade do seu trabalho.

\section{Referências}

Ayres, J. R. C. M. (2001). Sujeito, intersubjetividade e práticas de saúde. Ciência e Saúde Coletiva, 6(1), 63-72.

Ayres, J. R. C. M. (2004). O cuidado, os modos de ser (do) humano e as práticas de saúde. Saúde e Sociedade, 13(3), 16-29.

Boufleuer, J. P. (2001). Pedagogia da Ação Comunicativa. Ijuí, RS: Editora da Universidade Regional do Noroeste do Estado do Rio Grande do Sul.

Castrucci, B. C., Kamb, M. L., \& Hunt, K. (2002). Assessing the Center for Disease Control and Prevention's 1994 HIV Counseling, Testing, and Referral: Standards and Guidelines (How closely does practice conform to existing recommendations?). Sexually Transmitted Diseases, 29(7), 417-421.

Centers for Disease Control and Prevention. (1993). Technical Guidance on HIV Counseling, Testing e Referral: Standards and Guidelines. Atlanta, GA: Author.

Centers for Disease Control and Prevention. (1994). Technical Guidance on HIV Counseling, Testing e Referral: Standards and Guidelines. Atlanta, GA: Author.

Centers for Disease Control and Prevention. (2001). Revised Guidelines for HIV Counseling, Testing and Referral and Revised Recommendations for HIV Screening of Pregnant Women. Morbidity and Mortality Weekly Report, 50.

Corey, G. (1997). Counseling and psychotherapy: Theory and practice. Washington, DC: Brooks/ Cole

Dolcini, M. M., Canin, L., Gandelman, A., \& Skolnik, H. (2004). Theoretical domains: A heuristic for teaching behavioral theory in HIV/STD prevention courses. Health Promotion Practice, 5(4), 404-417.

Filgueiras, S. L., \& Deslandes, S. F. (1999). Avaliação das ações de aconselhamento: Análise de uma perspectiva de prevenção centrada na pessoa. Cadernos de Saúde Pública, 15(Supl. 2), 121-131. 
Gadamer, H. G. (2004). Verdade e método I: Traços fundamentais de uma hermenêutica filosófica (6. ed.). Petrópolis, RJ: Vozes.

Grinstead, O. A. (1997). HIV Counseling for Behavior Change. Aids Education and Prevention, 9(2), 125-132.

Holtgrave, D. R., Reiser, W. J., \& Franceisco, W. D. (1997). The evaluation of HIV Counseling and Testing Services: Making the most of limited resources. AIDS Education and Prevention, $9(\mathrm{Su}-$ ppl. B), 105-118.

Joint United Nations Programme on HIV/AIDS. (2000a). Tools for evaluating HIV voluntary counseling and testing. Best Practice Collection. Geneva, Switzerland: Author.

Joint United Nations Programme on HIV/AIDS. (2000b). Voluntary Counseling and Testing (VCT) Technical Update. Geneva, Switzerland: Author.

Joint United Nations Programme on HIV/AIDS, \& World Health Organization. (2000). Opening up the HIV/Aids Epidemic: Guidance on encouraging beneficial disclosure, ethical partner counseling and appropriate use of HIV case - Reporting (UNAIDS/0042E). Geneva, Switzerland: Joint United Nations Programme on HIV/AIDS.

Joint United Nations Programme on HIV/AIDS, \& World Health Organization. (2001). The impact of Voluntary Counseling and Testing: A global review of the benefits and challenges (UNAIDS/01.32E). Geneva, Switzerland: Author.

Kirschenbaum, H., \& Henderson, V. L. (Eds.). (1989). The Carl Rogers Reader - Selections from the Lifetime Work of America's Preeminent Psychologist. New York: Houghton Mifflin.

Lewis, E. C. (1970). The Psychology of Counseling. New York: Holt, Rinehart and Winston.

Ministério da Saúde. (1988). Manual de Condutas Clínicas. Brasília, DF: Autor.

Ministério da Saúde. (1989). Manual de Aconselhamento/AIDS. Brasília, DF: Autor.

Ministério da Saúde. (1993). Normas de organização e funcionamento dos Centros de Orientação e Apoio Sorológico. Brasília, DF: Autor.

Ministério da Saúde. (1994). Relatório do I Encontro de Avaliação de Centros de Apoio Sorológico. Campinas, SP: Autor.
Ministério da Saúde. (1996a). Relatório do II Encontro de Avaliação de Centros de Apoio Sorológico. Brasília, DF: Autor.

Ministério da Saúde. (1996b). Relatório do Seminário de Aconselhamento. Brasília, DF: Autor.

Ministério da Saúde. (1997). Aconselhamento em DST, HIV e Aids: Diretrizes e procedimentos básicos. Brasília, DF: Autor.

Ministério da Saúde. (1998). Manual de Treinamento de Aconselhamento em DST, HIV e Aids. Brasília, DF: Autor.

Ministério da Saúde. (1999). Aconselhamento: Um Desafio para a Prática Integral em Saúde - Avaliação das ações. Brasília, DF: Autor.

Ministério da Saúde. (2000). Diretrizes dos Centros de Testagem e Aconselhamento (CTA). Brasília, DF: Autor.

Ministério da Saúde. (2004). Aconselhamento em DST/HIV/Aids para a Atenção Básica. Brasília, DF: Autor.

Ministério da Saúde. (2005). Oficina de Aconselhamento em DST/HIV/Aids para a Atenção Básica. Brasília, DF: Autor.

Myers, T., Worthington, C., Haubrich, D. J., Ryder, K., \& Calzavara, L. (2003). HIV testing and counseling: Test providers' experiences of test practices. AIDS Education and Prevention, 15(4), 309-319.

Pattersson, C. H. (1973). Theories of Counseling and Psychotherapy. New York: Harper and Row.

Pattersson, E. L., \& Eisenberg, S. (2003). O processo de Aconselhamento. São Paulo, SP: Martins Fontes.

Rogers, C. R. (1981). Psicoterapia centrada en el cliente. Buenos Aires, Argentina: Paidós.

Rogers, C. R. (2001a). Tornar-se Pessoa. São Paulo, SP: Martins Fontes.

Rogers, C. R. (2001b). Sobre o Poder Pessoal. São Paulo, SP: Martins Fontes.

Rogers, C. R. (2005a). Psicoterapia e consulta psicológica. São Paulo, SP: Martins Fontes.

Rogers, C. R. (2005b). A pessoa como centro. São Paulo, SP: Editora Pedagógica e Universitária.

Santos, O. B. (1982). Aconselhamento psicológico e Psicoterapia. Auto-Afirmação - Um determinante básico. São Paulo, SP: Livraria Pioneira. 
Scheeffer, R. (1976). Teorias de Aconselhamento. São Paulo, SP: Atlas.

Sikkema, K. J., \& Bissett, R. T. (1997). Concepts, Goals and Techniques of Counseling: Review and Implications for HIV Counseling and Testing. AIDS Educations and Prevention, 9(Suppl. B), 14-26.

Souza, V., \& Czeresnia, D. (2007, set./dez.). Counseling discourse in anti-HIV testing services. Interface - Comunicação, Saúde, Educação, 11(23), 531-548.

Tyler, L. E. (1969). The Work of Counselor. Century Psychology Series. New York: Appleton Century Crofts.

Whiteley, J. M. (1999). The paradigms of Counseling Psychology. The Counseling Psychologist, 27(1), 14-31.

World Health Organization. (1990). Guidelines for Counseling about HIV Infection and Disease. AIDS Series 8. Geneva, Switzerland: Author.
World Health Organization. (1995a). Counseling for HIV/AIDS: A key to caring (WHO/GPA/TCA/ HCS/95.15). Geneva, Switzerland: Author.

World Health Organization. (1995b). Source Book for HIV/AIDS Counseling Training: Global Programme on AIDS (WHO/GPA/TCO/HCS/94.9). Geneva, Switzerland: Author.

World Health Organization. (2002). Increasing access to HIV Testing and Counseling: Report of a WHO Consultation, 19-21 November 2002, Geneva. Switzerland. Geneva, Switzerland: Author.
Recebido: 23/07/2012

$1^{a}$ revisão: 27/11/2012

$2^{a}$ revisão: 03/04/2013

Aceite final: 03/04/2013 